\title{
A Role for Protein Phosphatases 1,2A, and 2B in Cerebellar Long-Term Potentiation
}

\author{
Amor Belmeguenai and Christian Hansel \\ Department of Neuroscience, Erasmus University Medical Center, 3000 DR Rotterdam, The Netherlands
}

Cerebellar parallel fiber (PF)-Purkinje cell (PC) synapses can undergo postsynaptically expressed long-term depression (LTD) or longterm potentiation (LTP). PF-LTD induction requires the coactivity of the PF and CF (climbing fiber) inputs to PCs and a concomitant calcium transient and activation of protein kinase C (PKC). PF-LTP can be induced by PF activity alone and requires a lower calcium transient for its induction than PF-LTD. The cellular events triggering PF-LTP induction are not well characterized. At other types of synapses (e.g., in the hippocampus), bidirectional synaptic plasticity is under control of a kinase/phosphatase switch, with PKC and CaMKII (calcium/calmodulin-dependent kinase II) activity promoting LTP induction and phosphatase activity promoting LTD induction. Here, we have tested for the involvement of protein phosphatase 1 (PP1), PP2A, and PP2B (calcineurin) in cerebellar LTP induction using whole-cell patch-clamp recordings in rat cerebellar slices. LTP induction was blocked in the presence of the PP1/2A inhibitors okadaic acid and microcystin LR, the PP1 inhibitory peptide inhibitor-2, the PP2A inhibitor fostriecin, and the PP2B inhibitor cyclosporin A. LTP induction was not impaired by the PKC inhibitor chelerythrine. Conversely, LTD induction was not blocked by microcystin LR but instead was reduced when active PP2B was injected into PCs. These data indicate that a kinase/phosphatase switch controls bidirectional cerebellar plasticity, but in a manner "inverse" to the dependencies found at other types of synapses. Therefore, cerebellar LTP constitutes the only form of LTP described so far that depends on phosphatase rather than kinase activity.

Key words: cerebellum; Purkinje cell; LTP; LTD; kinase; phosphatase

\section{Introduction}

Synaptic information storage relies on the ability to potentiate or depress the efficacy of synaptic transmission on a long-term basis. These phenomena are termed long-term potentiation (LTP) and long-term depression (LTD), respectively. At glutamatergic synapses, changes in the phosphorylation state of AMPA receptor subunits can mediate this efficacy adjustment through biophysical changes at the individual receptor/channel level, or by modifying the insertion/internalization balance of AMPA receptor subunits (Bear and Linden, 2000). At hippocampal synapses, a kinase/phosphatase switch has been suggested to regulate the phosphorylation state of AMPA receptor subunits, involving calcium/calmodulin-dependent kinase II (CaMKII) and protein phosphatase 1 (PP1) (Lisman, 1989; Lisman and Zhabotinsky, 2001; Hedou and Mansuy, 2003; Munton et al., 2004). At these synapses, CaMKII activity promotes LTP induction, whereas PP1 activity promotes LTD induction. Both signaling cascades are calcium/calmodulin dependent but are activated by different calcium signal amplitudes, with LTP induction requiring a brief, high-amplitude calcium signal and LTD induction requiring a

Received July 13, 2005; revised 0ct. 12, 2005; accepted 0ct. 12, 2005.

This work was supported by a grant from NWO-VIDI (The Netherlands Organization for Scientific Research) to C.H. We thank Drs. Y. Elgersma and J. T. Weber for invaluable comments on this manuscript and members of the Hansel laboratory for helpful discussions.

Correspondence should be addressed to Dr. Christian Hansel, Department of Neuroscience, Erasmus University Medical Center, P.0. Box 1738, 3000 DR Rotterdam, The Netherlands. E-mail: c.hansel@erasmusmc.nl. DOI:10.1523/JNEUROSCI.2876-05.2005

Copyright $\odot 2005$ Society for Neuroscience ～0270-6474/05/2510768-05\$15.00/0 prolonged, low-amplitude calcium signal (Bienenstock et al., 1982; Hansel et al., 1997; Yang et al., 1999). PP1 itself does not bind calcium/calmodulin but is regulated by inhibitor-1 (I-1), the activity state of which is controlled by protein kinase A (PKA) and the calcium/calmodulin-dependent PP2B (also calcineurin) (Lisman, 1989). Phosphatase inhibition has indeed been shown to facilitate LTP induction (Herron and Malenka, 1994; Blitzer et al., 1998; Allen et al., 2000; Malleret et al., 2001; Woo et al., 2002). In contrast, LTD induction is dependent on phosphatase activation (Mulkey et al., 1993, 1994; Thiels et al., 1998, 2000; Ramakers et al., 2000; Morishita et al., 2001; Zeng et al., 2001).

In the cerebellum, LTD at parallel fiber (PF)-Purkinje cell (PC) synapses is seen as a cellular correlate of forms of cerebellar motor learning. PF-LTD is induced after prolonged simultaneous $\mathrm{PF}$ and climbing fiber (CF) stimulation and involves the activation of PKC and subsequent AMPA receptor internalization (for review, see Bear and Linden, 2000; Hansel et al., 2001; Ito, 2001). A postsynaptic form of LTP was only described recently (Lev-Ram et al., 2002; Coesmans et al., 2004). PF-LTP can be induced by PF stimulation alone, requires a lower calcium signal amplitude than PF-LTD induction (Coesmans et al., 2004), and is nitric oxide dependent in a cGMP-independent manner (Lev-Ram et al., 2002). In the cerebellum, PP1, PP2A, and PP2B are present (for review, see Ito, 2001), but their role has only been studied in the context of PF-LTD. Inhibition of protein phosphatases has been reported to facilitate PF-LTD induction (Ajima and Ito, 1995; Eto et al., 2002; Fuji and Hirano, 2002; Launey et al., 2004). 
Here, we examined the role of PP1, PP2A, and PP2B in PFLTP. We demonstrate that all three serine/threonine phosphatases are involved in PF-LTP induction but that the kinase/phosphatase switch controlling bidirectional synaptic plasticity in the cerebellum provides a mirror image of that shown at hippocampal synapses.

\section{Materials and Methods}

Slice preparation. Sagittal slices of the cerebellar vermis $(200-250 \mu \mathrm{m})$ were prepared from postnatal day 18-28 Sprague Dawley rats. Slices were kept in artificial CSF (ACSF) containing the following (in mM): 124 $\mathrm{NaCl}, 5 \mathrm{KCl}, 1.25 \mathrm{Na}_{2} \mathrm{HPO}_{4}, 2 \mathrm{MgSO}_{4}, 2 \mathrm{CaCl}_{2}, 26 \mathrm{NaHCO}_{3}$, and 10 D-glucose, bubbled with $95 \% \mathrm{O}_{2}$ and $5 \% \mathrm{CO}_{2}$. The perfusion ACSF was supplemented with $20 \mu \mathrm{M}$ bicuculline methiodide to block $\mathrm{GABA}_{\mathrm{A}}$ receptors. Whole-cell patch-clamp recordings were performed at room temperature using an EPC-10 amplifier (HEKA Elektronik, Lambrecht/ Pfalz, Germany). The recording electrodes were filled with a solution containing the following (in $\mathrm{mM}$ ): $9 \mathrm{KCl}, 10 \mathrm{KOH}, 120 \mathrm{~K}$-gluconate, 3.48 $\mathrm{MgCl}_{2}, 10$ HEPES, $4 \mathrm{NaCl}, 4 \mathrm{Na}_{2} \mathrm{ATP}, 0.4 \mathrm{Na}_{3} \mathrm{GTP}$, and 17.5 sucrose, $\mathrm{pH}$ adjusted to 7.25. All drugs were purchased from Sigma (St. Louis, MO), except for protein phosphatase inhibitor-2 (I-2; New England BioLabs, Beverly, MA), cyclosporin A (Tocris, Ellisville, MO), H-7 dihydrochloride (H-7; Tocris), and active PP2B (Upstate Biotechnology, Lake Placid, $\mathrm{NY})$.

Electrophysiology. Currents were filtered at $3 \mathrm{kHz}$, digitized at $8 \mathrm{kHz}$, and acquired using PULSE software. In voltage-clamp mode, holding potentials in the range of -60 to $-75 \mathrm{mV}$ were chosen to prevent spontaneous spike activity that might escape voltage clamp because of the poor space-clamp characteristics that are typical for PC recordings. For extracellular stimulation, standard patch pipettes were used that were filled with external saline. CFs were stimulated in the granule cell layer, and PFs were stimulated in the molecular layer. Test responses were evoked at a frequency of $0.05 \mathrm{~Hz}$ using $\sim 3 \mu \mathrm{A}$ pulses that were applied for $500 \mu \mathrm{s}$ (LTP) or $700 \mu \mathrm{s}$ (LTD). In all experiments, cells were switched to current-clamp mode for tetanization. Recordings were excluded from the study if the series or input resistance varied by $>15 \%$ over the course of the experiment $(\leq 20 \%$ changes were allowed when the responses changed by $\geq 40 \%$ ). All values are shown as percentages of baseline \pm SEM. For statistical analysis, we used the paired Student's $t$ test and the Mann-Whitney $U$ test, when appropriate.

\section{Results}

\section{PF-LTP is a postsynaptic phenomenon, the induction of} which is PKC independent

To examine the role of protein phosphatases in PF-LTP induction, we performed whole-cell patch-clamp recordings from PCs in rat cerebellar slices. Test responses were monitored in voltageclamp mode before and after tetanization. PF-LTP was observed after PF stimulation at $1 \mathrm{~Hz}$ for $5 \mathrm{~min}$ in current-clamp mode (Fig. 1A). After tetanization, the potentiation of EPSC amplitudes amounted to $130.8 \pm 10.2 \%$ of baseline $(n=11 ; t=15-20$ min after), reaching statistical significance ( $p<0.05$; paired Student's $t$ test). In a subset of these recordings, we measured the paired-pulse facilitation ratio by applying two pulses at an interval of $100 \mathrm{~ms}$. After tetanization, the paired-pulse facilitation ratio was unaltered $(100.5 \pm 2.2 \% ; n=7 ; t=15-20 \mathrm{~min}$ after; $p>0.05$; paired Student's $t$ test) (Fig. $1 \mathrm{~B}$ ), confirming previous reports that this form of LTP is a postsynaptic phenomenon (LevRam et al., 2002; Coesmans et al., 2004). As a first experimental manipulation, we attempted to induce LTP in the presence of chelerythrine, a membrane-permeant inhibitor of the catalytic site of PKC. When chelerythrine was present in the bath throughout the experiment $(10 \mu \mathrm{M})$, LTP could still be induced (121.3 \pm $8.7 \% ; n=7$ ) (Fig. 1C). LTP monitored in the presence of chelerythrine was not statistically different from the LTP described above ( $p>0.05$; Mann-Whitney $U$ test), indicating that LTP is
A

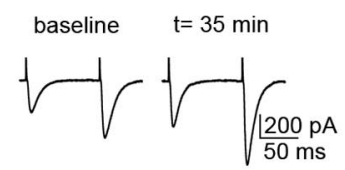

C
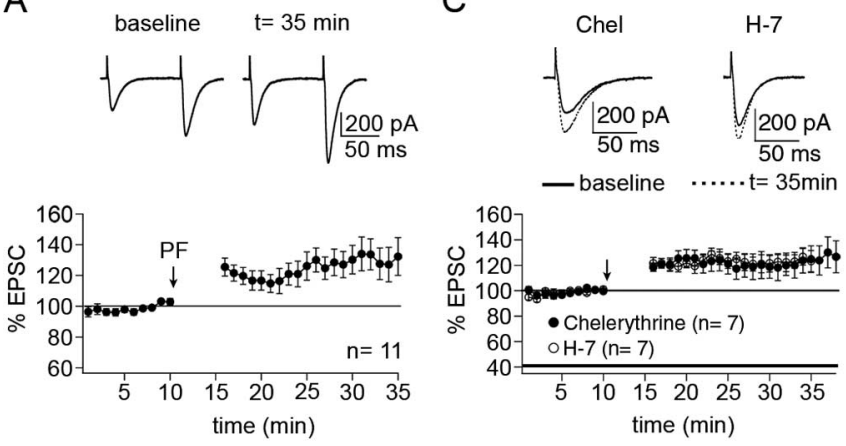

B
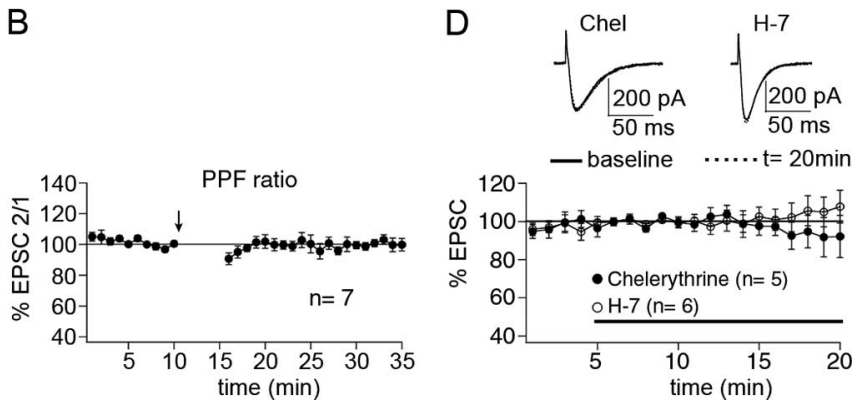

Figure 1. Postsynaptic PF-LTP is PKC independent. A, PF-LTP can be induced by PF stimulation at $1 \mathrm{~Hz}$ for $5 \mathrm{~min}(n=11)$. Each data point represents the average of three successive test responses evoked at $0.05 \mathrm{~Hz}$. The top traces show EPSCs before and after LTP induction. $\boldsymbol{B}$, Paired-pulse facilitation ratio (EPSC2/1) obtained from a subset of the LTP cells shown in $A(n=$ 7). C, Neither the PKC inhibitor chelerythrine ( $10 \mu \mathrm{m} ; n=7)$ nor the general kinase inhibitor $\mathrm{H}-7$ $(50 \mu \mathrm{m} ; n=7)$ blocks LTP induction. $\boldsymbol{D}$, In the absence of tetanization, neither chelerythrine $(n=5)$ nor H-7 $(n=6)$ affects EPSC amplitudes. The bars in Cand D indicate the presence of the drugs in the bath. Error bars are mean \pm SEM.

PKC independent. In control experiments, chelerythrine did not change EPSC amplitudes (93.7 $\pm 7.3 \%$; $n=5$; last 5 min) (Fig. $1 D)$. To test for the effect of a more general kinase inhibitor, we applied the LTP protocol in the presence of the protein kinase inhibitor H-7 $(50 \mu \mathrm{M})$, a relatively unselective kinase inhibitor that inhibits PKC, PKA, and protein kinase G (PKG). LTP could still be induced when $\mathrm{H}-7$ was in the bath $(123.5 \pm 6.1 \% ; n=7)$ (Fig. 1C). LTP recorded in the presence of H-7 was not statistically different from the LTP shown in Figure $1 A(p>0.05$; Mann-Whitney $U$ test). In control experiments, H-7 did not change EPSC amplitudes $(104.3 \pm 6.7 \% ; n=6)$ (Fig. 1D).

\section{PF-LTP is dependent on the activation of PP1, PP2A, and PP2B}

To study the involvement of protein phosphatases, we began with the PP1/2A inhibitor okadaic acid $(1 \mu \mathrm{M})$. When okadaic acid was in the bath from $5 \mathrm{~min}$ before to $5 \mathrm{~min}$ after tetanization, LTP induction was blocked, and a depression was observed instead $(83.5 \pm 6.1 \% ; n=7 ; 15-20 \mathrm{~min}$ after) (Fig. $2 A)$. LTP, as obtained under control conditions (Fig. $1 A$ ), was significantly inhibited $(p<0.01$; Mann-Whitney $U$ test $)$. To confirm that postsynaptic phosphatases are involved, we also tested the PP1/2A inhibitor microcystin LR $(10 \mu \mathrm{M})$, which was added to the pipette saline. In the presence of microcystin LR, the tetanization led to LTD instead of LTP $(65.1 \pm 4.4 \% ; n=7 ; 15-20 \mathrm{~min}$ after) (Fig. $2 C)$. This depression was significantly different from the LTP observed under control conditions ( $p<0.01$; Mann-Whitney $U$ test). In the absence of tetanization, EPSC amplitudes remained stable in the presence of okadaic acid $(97.5 \pm 2.2 \% ; n=5$; last $5 \mathrm{~min})$ (Fig. 

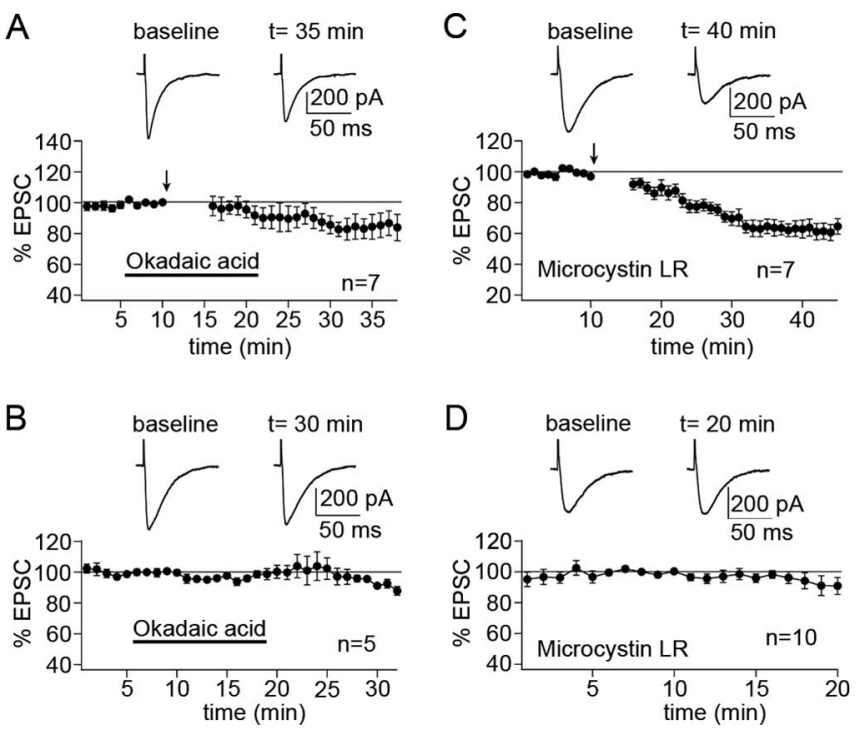

Figure 2. PP1/2A inhibitors block PF-LTP induction. $A$, Bath application of the PP1/2A inhibitor okadaic acid $(1 \mu \mathrm{M})$ blocks LTP induction $(n=7)$. $\boldsymbol{B}$, In the absence of tetanization, okadaic acid does not affect EPSC amplitudes $(n=5)$. C, When the PP1/2A inhibitor microcystin LR (10 $\mu \mathrm{m})$ is added to the pipette saline, LTP induction is impaired $(n=7)$. $\boldsymbol{D}$, The same pipette saline does not cause the depression observed in $C$ in the absence of tetanization $(n=10)$. Error bars are mean \pm SEM.

$2 B)$ and microcystin $\operatorname{LR}(93.5 \pm 5.1 \% ; n=10$; last $5 \mathrm{~min})$ (Fig. $2 D)$, respectively.

To be able to discern the differences between the effects of PP1 and PP2A inhibition, we next used more specific phosphatase inhibitors. Several endogenous phosphatase inhibitors have been characterized that specifically target PP1, including I-1, I-2, and CPI-17 (for review, see Oliver and Shenolikar, 1998). I-2 is a 204 aa protein that specifically inhibits the catalytic subunit of PP1. When I-2 (100 nM) was added to the pipette saline, the LTP protocol caused a slight depression instead $(92.2 \pm 6.1 \%, n=7$; 15-20 min after) (Fig. 3A). This effect was significantly different from the LTP seen under control conditions ( $p<0.01$; MannWhitney $U$ test). To test for the involvement of PP2A, we added the specific PP2A inhibitor fostriecin (50 nM) to the pipette saline. In the presence of fostriecin, the tetanization caused LTD $(74.3 \pm 11.1 \% ; n=7 ; 15-20$ min after) (Fig. 3B). This depression was again significantly different from the LTP shown in Figure $1 A(p<0.01$; Mann-Whitney $U$ test $)$. Finally, we tested for the involvement of PP2B by adding the specific PP2B inhibitor cyclosporin A $(100 \mu \mathrm{M})$ to the bath. Once more, we observed LTD instead of LTP $(60.5 \pm 7.3 \% ; n=8 ; 15-20 \mathrm{~min}$ after) (Fig. $3 C$ ), and this difference again was significant ( $p<0.01$; Mann-Whitney $U$ test). All three inhibitors had no effect, or far milder effects, on EPSC amplitudes in the absence of tetanization (I-2: $101.3 \pm$ $8.5 \%, n=4$; fostriecin: $99.5 \pm 4.0 \%, n=9$; cyclosporin A: $90.1 \pm$ $2.7 \%, n=4$; all last $5 \mathrm{~min}$ ) (Fig. $3 D$ ).

\section{PF-LTD is phosphatase independent}

As shown above, PF-LTP induction is PKC independent but requires protein phosphatase activity. To test for the role of protein phosphatases in LTD induction, we first established PF-LTD under control conditions. Paired PF and CF stimulation at $1 \mathrm{~Hz}$ for $5 \mathrm{~min}$ led to the induction of PF-LTD $(78.8 \pm 7.2 \% ; n=8 ; 15-20$ min after) (Fig. $4 A$ ), which reached statistical significance $(p<$ 0.05; paired Student's $t$ test). We next wanted to examine the effect of protein phosphatase inhibition, using a relatively unspe-
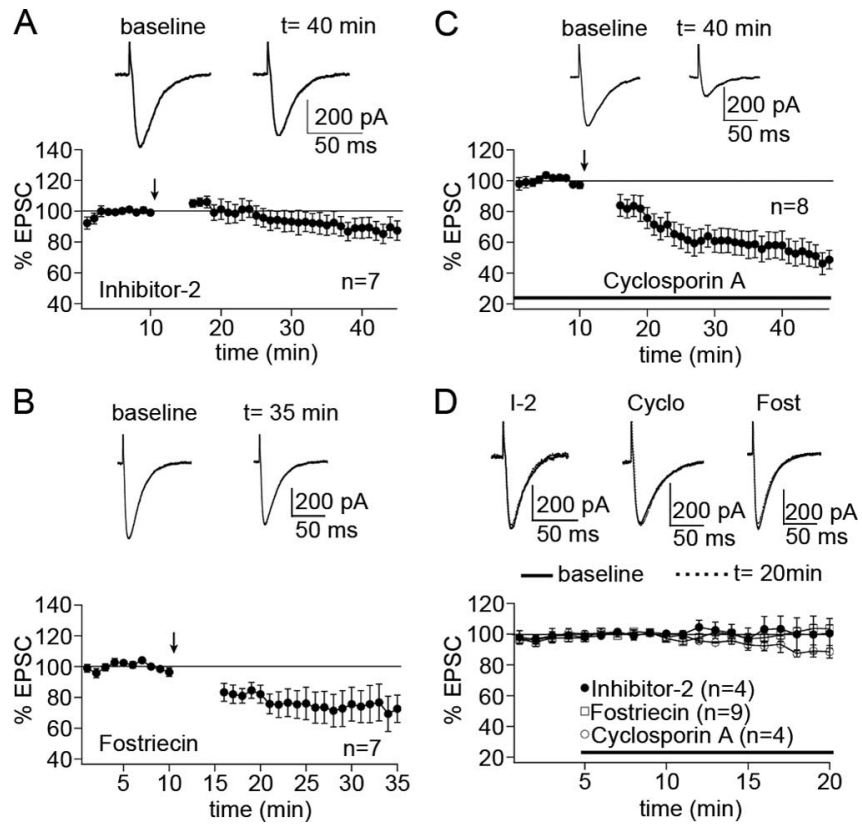

Figure 3. $P P 1, P P 2 A$, and $P P 2 B$ are required for PF-LTP induction. $A, I-2$, a PP1 inhibitory protein, blocks PF-LTP induction when added to the pipette saline ( $100 \mathrm{~nm} ; n=7)$. $\boldsymbol{B}$, The PP2A inhibitor fostriecin, which is also added to the pipette saline (50 nm), blocks PF-LTP induction $(n=7)$. C, Bath application of the PP2B-selective inhibitor cyclosporin A (100 $\mu \mathrm{M})$ blocks PF-LTP induction as well $(n=8)$. $\boldsymbol{D}$, In control experiments, neither I-2 $(n=4)$, nor fostriecin $(n=9)$, nor cyclosporin $A(n=4)$ affects EPSC amplitudes. The bars in $\boldsymbol{C}$ and $\boldsymbol{D}$ indicate the presence of cyclosporin $A$ in the bath. Error bars are mean \pm SEM.

cific phosphatase inhibitor with a large effect on PF-LTP. To this end, we applied microcystin LR $(10 \mu \mathrm{M})$ to the pipette saline. In the presence of microcystin LR, PF-LTD was not blocked but rather slightly enhanced $(73.5 \pm 9.7 \% ; n=9 ; 15-20$ min after $)$ (Fig. $4 B$ ), but this effect did not reach statistical significance $(p>$ 0.05; Mann-Whitney $U$ test). As shown in Figure 1, the kinase inhibitors chelerythrine and H-7 do not affect LTP induction. To verify the kinase dependence of LTD induction, we applied the LTD protocol, when chelerythrine $(10 \mu \mathrm{M})$ or H-7 $(50 \mu \mathrm{M})$ was present in the bath. Both drugs blocked LTD induction (chelerythrine: $111.9 \pm 6.8 \%, n=5 ; \mathrm{H}-7: 104.0 \pm 4.9 \%, n=6 ; 15-20$ min after) (Fig. $4 B$ ). For both chelerythrine and $\mathrm{H}-7$, respectively, these values differed significantly from the PF-LTD shown in Figure $4 A(p<0.05$; Mann-Whitney $U$ test $)$. As shown in Figure $4 B$, microcystin LR does not block PF-LTD. The opposite strategy is to inject an active phosphatase with the pipette saline into PCs. The term "active" refers to the ability of the purified enzyme to perform its enzymatic function without further modification (such as phosphorylation) when the proper cofactors and substrates are present. A limitation of this approach is that, although the injected phosphatase is in an active state, its true enzymatic activity remains unknown, because it is not obvious which cofactors and/or inhibitors it is exposed to. We thus decided to inject active PP2B $(5 \mu \mathrm{g} / \mathrm{ml})$ and to test for its effect on PF-LTD induction. This constellation allows the assumption that $\mathrm{PP} 2 \mathrm{~B}$, as a calcium/calmodulin-binding phosphatase, will be exposed to the calcium transient caused by $\mathrm{PF}$ and $\mathrm{CF}$ tetanization, providing a key requirement for $\mathrm{PP} 2 \mathrm{~B}$ activation. Under these conditions, PF-LTD induction was blocked (109.3 $\pm 7.8 \% ; n=$ 8; 15-20 min after) (Fig. 4C). This inhibition was statistically significant ( $p<0.05$; Mann-Whitney $U$ test). We also tested for the effect of PP2B injection on PF-LTP induction. When active $\mathrm{PP} 2 \mathrm{~B}$ was added to the pipette saline, LTP induction was unaf- 
A
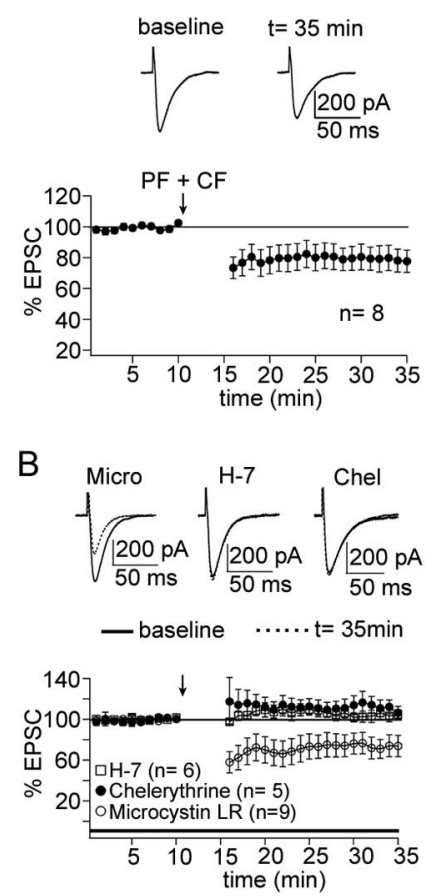

C
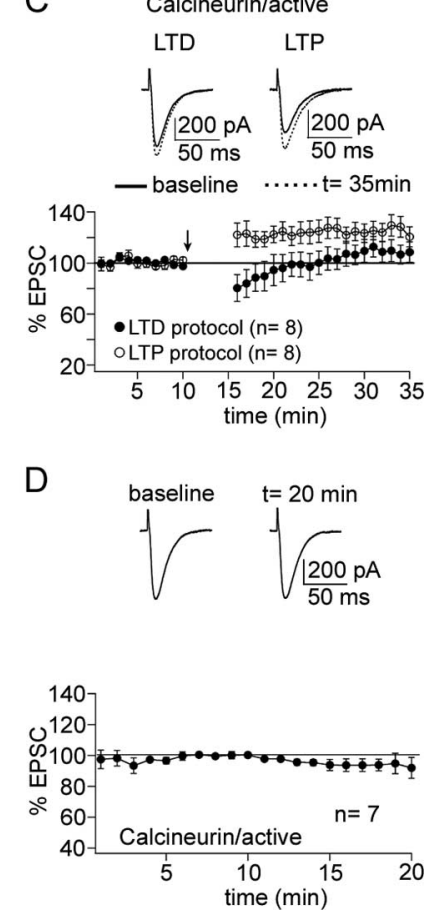

Figure 4. PF-LTD is not phosphatase dependent. $A$, PF-LTD can be induced after paired PF + CF stimulation at $1 \mathrm{~Hz}$ for $5 \mathrm{~min}(n=8)$. The top traces show EPSCs before and after LTD induction. $\boldsymbol{B}$, PF-LTD is not impaired when microcystin $\mathrm{LR}(10 \mu \mathrm{m})$ is added to the pipette saline $(n=9)$. PF-LTD was blocked in the presence of chelerythrine $(10 \mu \mathrm{m} ; n=5)$ and H-7 (50 $\mu \mathrm{m}$; $n=6)$, respectively. C, When active calcineurin is added to the pipette saline $(5 \mu \mathrm{g} / \mathrm{ml})$, paired $\mathrm{PF}+$ CF stimulation no longer causes a depression $(n=8)$, whereas PF-LTP induction is unaffected $(n=8)$. $\boldsymbol{D}$, In the absence of tetanization, adding calcineurin does not affect EPSC amplitudes $(n=7)$. Error bars are mean \pm SEM.

fected $(126.3 \pm 6.1 \% ; n=8 ; 15-20$ min after) (Fig. $4 C)$. The LTP monitored in the presence of $\mathrm{PP} 2 \mathrm{~B}$ did not differ from the basic LTP shown in Figure $1 A$ ( $p>0.05$; Mann-Whitney $U$ test). In the absence of tetanization, PP2B injection had no effect on EPSC amplitudes (96.7 $\pm 4.7 ; n=7$ ) (Fig. 4D).

\section{Discussion \\ An "inverse" kinase/phosphatase switch for cerebellar synaptic plasticity}

The data shown here indicate that the serine/threonine phosphatases PP1, PP2A, and PP2B are involved in PF-LTP induction. In addition, they demonstrate that downstream of the tetanizationevoked calcium transient, the signaling cascades for LTP and LTD induction diverge: whereas LTD induction is PKC dependent (for review, see Bear and Linden, 2000; Hansel et al., 2001; Ito, 2001), it does not require phosphatase activity (tested in this study for PP1/2A) but is rather blocked by phosphatase activity (shown here for PP2B). Conversely, PF-LTP induction is not PKC dependent but can be blocked (and reversed to LTD) by inhibition of PP1, PP2A, and PP2B, respectively. In addition to the $\mathrm{PKC}$ inhibitor chelerythrine, we also used the more general kinase inhibitor $\mathrm{H}-7$, which inhibits PKC, PKA, and PKG. In the presence of H-7, LTD was blocked, but LTP was unaffected. These results show that LTP is not only independent of PKC activity but also does not require PKA or PKG activity, suggesting a general kinase independence. To further characterize the phosphatase dependence of LTP, we also tested for the effect of active PP2B injection on LTP induction. Although phosphatase inhibition blocked LTP induction, we did not observe enhanced LTP when active PP2B was injected into the cells. It seems likely that the level of activation of endogenous $\mathrm{PP} 2 \mathrm{~B}$ by the LTP protocol is sufficient to saturate downstream events (e.g., dephosphorylation of I-1), so that additional active PP2B does not enhance EPSC amplitudes any further.

The kinase/phosphatase switch mechanism described here provides a mirror image of the CaMKII/PP1 switch suggested for hippocampal LTP and LTD (Lisman, 1989; Lisman and Zhabotinsky, 2001; Hedou and Mansuy, 2003; Munton et al., 2004), in which PP2B also takes part by controlling I-1, which in turn regulates PP1 (Lisman, 1989). There is evidence that the "hippocampal scenario," in which kinase activity promotes LTP and phosphatase activity promotes LTD, is more widespread than the inverse cerebellar scenario described here, because a phosphatase-dependent induction of LTD has also been reported in the visual cortex (Kirkwood and Bear, 1994) and the amygdala (Lin et al., 2003). A remarkable exception to the hippocampal scenario is provided by hippocampal LTD induced by activation of metabotropic glutamate receptors (GluRs), which is PKC dependent (Bear and Linden, 2000).

A caveat of this study is that protein phosphatase inhibition is notoriously problematic because of limited selectivity of the available inhibitors. This certainly holds true for okadaic acid and microcystin LR, both of which are not selective for PP1 versus PP2A inhibition. We have tried to address this problem by additionally using more specific inhibitors for PP1 (I-2), PP2A (fostriecin), and $\mathrm{PP} 2 \mathrm{~B}$ (cyclosporin A), which show high selectivity within the concentration ranges used. Previous studies have shown that phosphatase inhibition promotes LTD induction. This effect has been reported for PP1/2A (Ajima and Ito, 1995), myosin/moesin phosphatase (which contains the catalytic subunit of PP1) (Eto et al., 2002), PP2A (Launey et al., 2004), as well as PP2B (Fujii and Hirano, 2002), suggesting that indeed all three types of serine/threonine phosphatases might play a role in PFLTP. It is well established that PP1 and PP2B act as a tandem, with PP2B controlling the PP1 regulator I-1 (Lisman, 1989). Another PP1 inhibitor is CPI-17, which is activated by PKC. This pathway has been shown to be required for LTD induction (Eto et al., 2002), suggesting that PP1 and PP2B counteract the PKCmediated phosphorylation events promoting LTD. What exact role PP2A plays is less clear, because its interaction with PP1 and $\mathrm{PP} 2 \mathrm{~B}$ and its regulation have not been studied in as much detail (Oliver and Shenolikar, 1998).

\section{Phosphorylation of AMPA receptor subunits}

The kinase/phosphatase switch model suggests that the phosphorylation state of an AMPA receptor subunit determines whether LTP or LTD occurs. This phosphorylation-dependent switch can be achieved through a modification of channel properties and/or a change in the delivery/internalization rate of AMPA receptor subunits. The relevant phosphorylation sites have been examined at hippocampal synapses, which contain GluR1 and GluR2 subunits. GluR1 has two identified phosphorylation sites in the intracellular C-terminal domain, namely Ser831 (a CaMKII and PKC phosphorylation site) and Ser-845 (a PKA phosphorylation site). Interestingly, it seems that the most simple scenario, namely one phosphorylation site being in a phosphorylated state during LTP and in a dephosphorylated state during LTD, does not hold true. Rather, it has been shown that Ser-831 is phosphorylated during LTP and dephosphorylated during depotentiation, whereas Ser-845 is dephosphorylated during LTD (Lee et al., 2000). AMPA receptors in cerebellar PCs do not contain GluR1 subunits, shifting GluR2 into the spotlight. 
It has indeed been shown that in PF-LTD, PKC activation leads to a phosphorylation of GluR2 at Ser-880 (Chung et al., 2003). It remains to be examined what the molecular targets of PP1, PP2A, and PP2B are in PF-LTP. Although this and other studies highlight the importance of phosphorylation events in LTD and LTP induction, AMPA receptor subunit trafficking is under control of additional factors. It has, for example, recently been shown in cultured cortical neurons that nitric oxide (NO)-dependent $S$-nitrosylation of $N$-ethylmaleimide-sensitive factor promotes GluR2 insertion (Huang et al., 2005). This cascade might be crucial for PF-LTP induction as well, because it has been suggested that not only PF-LTD but also PF-LTP is NO dependent (LevRam et al., 2002).

Here, we show that bidirectional synaptic plasticity at cerebellar PF-PC synapses is under control of a kinase/phosphatase switch mechanism, which operates in an inverse manner compared with the switch mechanism observed at hippocampal synapses. It is possible that other activity-dependent cellular events, such as NO-dependent $S$-nitrosylation, are also involved in the determination of the polarity of synaptic gain change.

\section{References}

Ajima A, Ito M (1995) A unique role of protein phosphatases in cerebellar long-term depression. NeuroReport 6:297-300.

Allen PB, Hvalby O, Jensen V, Errington ML, Ramsay M, Chaudry FA, Bliss TVP, Storm-Mathisen J, Morris RGM, Andersen P, Greengard P (2000) Protein phosphatase-1 regulation in the induction of long-term potentiation: heterogeneous molecular mechanisms. J Neurosci 20:3537-3543.

Bear MF, Linden DJ (2000) The mechanisms and meaning of long-term synaptic depression in the mammalian brain. In: The synapse (Cowan WN, Südhof T, Stevens CF, eds), pp 455-517. Baltimore: Johns Hopkins UP.

Bienenstock EL, Cooper LN, Munroe PW (1982) Theory for the development of neuron selectivity: orientation specificity and binocular interaction in visual cortex. J Neurosci 2:32-48.

Blitzer RD, Connor JH, Brown GP, Wong T, Shenolikar S, Iyengar R, Landau EM (1998) Gating of CaMKII by cAMP-regulated protein phosphatase activity during LTP. Science 280:1940-1943.

Chung HJ, Steinberg JP, Huganir RL, Linden DJ (2003) Requirement of AMPA receptor GluR2 phosphorylation for cerebellar long-term depression. Science 300:1751-1755.

Coesmans M, Weber JT, De Zeeuw CI, Hansel C (2004) Bidirectional parallel fiber plasticity in the cerebellum under climbing fiber control. Neuron 44:691-700.

Eto M, Bock R, Brautigan DL, Linden DJ (2002) Cerebellar long-term synaptic depression requires PKC-mediated activation of CPI-17, a myosin/ moesin phosphatase inhibitor. Neuron 36:1145-1158.

Fujii H, Hirano T (2002) Calcineurin regulates induction of late phase of cerebellar long-term depression in rat cultured Purkinje neurons. Eur J Neurosci 16:1777-1788.

Hansel C, Artola A, Singer W (1997) Relation between dendritic Ca ${ }^{2+}$ levels and the polarity of synaptic long-term modifications in rat visual cortex neurons. Eur J Neurosci 9:2309-2322.

Hansel C, Linden DJ, D'Angelo E (2001) Beyond parallel fiber LTD: the diversity of synaptic and non-synaptic plasticity in the cerebellum. Nat Neurosci 4:467-475.

Hedou G, Mansuy IM (2003) Inducible molecular switches for the study of long-term potentiation. Philos Trans R Soc Lond B Biol Sci 358:797-804.

Herron CE, Malenka RC (1994) Activity-dependent enhancement of synaptic transmission in hippocampal slices treated with the phosphatase inhibitor calyculin A. J Neurosci 14:6013-6020.
Huang Y, Man HY, Sekine-Aizawa Y, Han Y, Juluri K, Luo H, Cheah J, Lowenstein C, Huganir RL, Snyder SH (2005) S-nitrosylation of $\mathrm{N}$-ethylmaleimide sensitive factor mediates surface expression of AMPA receptors. Neuron 46:533-540.

Ito M (2001) Cerebellar long-term depression: characterization, signal transduction, and functional roles. Physiol Rev 81:1143-1194.

Kirkwood A, Bear MF (1994) Homosynaptic long-term depression in the visual cortex. J Neurosci 14:3404-3412.

Launey T, Endo S, Sakai R, Harano J, Ito M (2004) Protein phosphatase 2A inhibition induces cerebellar long-term depression and declustering of synaptic AMPA receptor. Proc Natl Acad Sci USA 101:676-681.

Lee HK, Barbarosie M, Kameyama K, Bear MF, Huganir RL (2000) Regulation of distinct AMPA receptor phosphorylation sites during bidirectional synaptic plasticity. Nature 405:955-959.

Lev-Ram V, Wong ST, Storm DR, Tsien RY (2002) A new form of cerebellar long-term potentiation is postsynaptic and depends on nitric oxide but not cAMP. Proc Natl Acad Sci USA 99:8389-8393.

Lin CH, Lee CC, Gean PW (2003) Involvement of a calcineurin cascade in amygdala depotentiation and quenching of fear memory. Mol Pharmacol 63:44-52.

Lisman J (1989) A mechanism for the Hebb and the anti-Hebb processes underlying learning and memory. Proc Natl Acad Sci USA 86:9574-9578.

Lisman J, Zhabotinsky AM (2001) A model of synaptic memory: a CaMKII/ PP1 switch that potentiates transmission by organizing an AMPA receptor anchoring assembly. Neuron 31:191-201.

Malleret G, Haditsch U, Genoux D, Jones MW, Bliss TVP, Vanhoose AM, Weitlauf C, Kandel ER, Winder DG, Mansuy IM (2001) Inducible and reversible enhancement of learning, memory, and long-term potentiation by genetic inhibition of calcineurin. Cell 104:675-686.

Morishita W, Connor JH, Xia H, Quinlan EM, Shenolikar S, Malenka RC (2001) Regulation of synaptic strength by protein phosphatase 1 . Neuron 32:1133-1148.

Mulkey RM, Herron CE, Malenka RC (1993) An essential role for protein phosphatases in hippocampal long-term depression. Science 261:1051-1055

Mulkey RM, Endo S, Shenolikar S, Malenka RC (1994) Involvement of a calcineurin/inhibitor-1 phosphatase cascade in hippocampal long-term depression. Nature 369:486-488.

Munton RP, Vizi S, Mansuy IM (2004) The role of protein phosphatase-1 in the modulation of synaptic and structural plasticity. FEBS Lett 567:121-128.

Oliver CJ, Shenolikar S (1998) Physiologic importance of protein phosphatase inhibitors. Front Biosci 3:961-972.

Ramakers GMJ, Heinen K, Gispen WH, De Graan PNE (2000) Long-term depression in the CAl field is associated with a transient decrease in preand postsynaptic PKC substrate phosphorylation. J Biol Chem 275:28682-28687.

Thiels E, Norman ED, Barrionuevo G, Klann E (1998) Transient and persistent increases in protein phosphatase activity during long-term depression in the adult hippocampus in vivo. Neuroscience 86:1023-1029.

Thiels E, Kanterewicz BI, Knapp LT, Barrionuevo G, Klann E (2000) Protein phosphatase-mediated regulation of protein kinase $\mathrm{C}$ during long-term depression in the adult hippocampus in vivo. J Neurosci 20:7199-7207.

Woo NH, Abel T, Nguyen PV (2002) Genetic and pharmacological demonstration of a role for cyclic AMP-dependent protein kinase-mediated suppression of protein phosphatases in gating the expression of late LTP. Eur J Neurosci 16:1871-1876.

Yang SN, Tang YG, Zucker RS (1999) Selective induction of LTP and LTD by postsynaptic $\left[\mathrm{Ca}^{2+}\right]_{\mathrm{i}}$ elevation. J Neurophysiol 81:781-787.

Zeng H, Chattarji S, Barbarosie M, Rondi-Reig L, Philpot BD, Miyakawa T, Bear MF, Tonegawa S (2001) Forebrain-specific calcineurin knockout selectively impairs bidirectional synaptic plasticity and working/episodiclike memory. Cell 107:617-629. 